\title{
Earthquake Probability Assessment for the Active Faults in Central Taiwan: A Case Study
}

\author{
Yi-Rui Lee ${ }^{1, *}$, Chin-Tung Cheng ${ }^{1}$, Kuo-Shih Shao ${ }^{1}$, Yi-Rung Chuang ${ }^{2}$, Jyr-Ching Hu ${ }^{2}$, Tzu-Hua Lai ${ }^{3}$, and \\ Shih-Ting $\mathrm{Lu}^{3}$ \\ ${ }^{1}$ Disaster Prevention Technology Research Center, Sinotech Engineering Consultants, Inc., Taipei, Taiwan, R.O.C. \\ ${ }^{2}$ Department of Geosciences, National Taiwan University, Taipei, Taiwan, R.O.C. \\ ${ }^{3}$ Central Geological Survey, MOEA, Taipei, Taiwan, R.O.C.
}

Received 29 October 2015, revised 23 March 2016, accepted 24 March 2016

\begin{abstract}
Frequent high seismic activities occur in Taiwan due to fast plate motions. According to the historical records the most destructive earthquakes in Taiwan were caused mainly by inland active faults. The Central Geological Survey (CGS) of Taiwan has published active fault maps in Taiwan since 1998. There are 33 active faults noted in the 2012 active fault map. After the Chi-Chi earthquake, CGS launched a series of projects to investigate the details to better understand each active fault in Taiwan. This article collected this data to develop active fault parameters and referred to certain experiences from Japan and the United States to establish a methodology for earthquake probability assessment via active faults. We consider the active faults in Central Taiwan as a good example to present the earthquake probability assessment process and results. The appropriate "probability model" was used to estimate the conditional probability where $M \geq 6.5$ and $M \geq 7.0$ earthquakes. Our result shows that the highest earthquake probability for $M \geq 6.5$ earthquake occurring in 30, 50, and 100 years in Central Taiwan is the Tachia-Changhua fault system. Conversely, the lowest earthquake probability is the Chelungpu fault. The goal of our research is to calculate the earthquake probability of the 33 active faults in Taiwan. The active fault parameters are important information that can be applied in the following seismic hazard analysis and seismic simulation.
\end{abstract}

Key words: Active fault, Logic tree, Characteristic earthquake model, Probability model

Citation: Lee, Y. R., C. T. Cheng, K. S. Shao, Y. R. Chuang, J. C. Hu, T. H. Lai, and S. T. Lu, 2016: Earthquake probability assessment for the active faults in Central Taiwan: A case study. Terr. Atmos. Ocean. Sci., 27, 341-357, doi: 10.3319/TAO.2016.03.24.01(TEM)

\section{INTRODUCTION}

\subsection{Earthquake Hazards and Active Faults in Taiwan}

Taiwan is located at the boundary between the Philippine Sea Plate to the east and the Eurasian Plate to the west. These two plates have a convergence rate of about $80 \mathrm{~mm} \mathrm{yr}^{-1}$ in a $\sim \mathrm{N} 118 \mathrm{E}$ direction (Seno 1977; Angelier 1986; Yu et al. 1997). There have been frequent high seismic activities in Taiwan due to the very fast plate motions. According to historical records the most destructive earthquakes in Taiwan were caused mainly by inland active faults. For example, the Chi-Chi earthquake in 1999 was attributed to the Chelungpu fault. The Hsinchu-Taichung earthquake in 1935 was attributed to the Shihtan-Tuntzuchiao fault system. These two events resulted in thousands of casualties.

\footnotetext{
* Corresponding author

E-mail:yirui@sinotech.org.tw
}

It is not easy to avoid land usage near active faults in Taiwan because of the population growth and urban development. However, people can still minimize damage via certain methods, such as appropriate building code for safe construction and earthquake insurance for loss protection. These methods require credible PSHA (Probabilistic Seismic Hazard Analysis) which includes the earthquake probabilities for active faults.

Since 1977, Bonilla (1977) and Hsu and Chang (1979) plotted active fault maps in Taiwan, which were only preliminary results in a small scale (1/2000000). In 2000, National Central University (NCU) integrated the researches from Tsai et al. (1998) and Lee (1999) to develop the NCU edition of active fault map. Later, Cheng (2002) added three blind faults to the active fault map of NCU for PSHA 
calculation. The Central Geological Survey (CGS) of Taiwan published active fault maps in Taiwan since 1998. It lists 33 active faults in the 2012 active fault map. After the Chi-Chi earthquake CGS launched a series of projects to investigate the detailed data to better understand each active fault in Taiwan. This article compiles these data to develop active fault parameters. This study also describes a process for estimating active fault earthquake probability assessment based on experiences from Japan and the United States. We studied active faults in Central Taiwan as an example to present the earthquake probability assessment process and results.

\subsection{Relative Studies and Reviews from Other Countries}

In 1979 the National Earthquake Prediction Evaluation Council (NEPEC) was established to advise the Director of the U.S. Geological Survey (USGS) on the potential of damaging earthquakes. In the mid-1980s NEPEC recommended that a working group be convened to evaluate the potential of large earthquakes in both southern California and the San Francisco Bay Region (SFBR). The first report was titled the Working Group on California Earthquake Probabilities 1988 (WGCEP 1988). The earthquake probability assessment had undergone six revisions. The first three versions focused mainly on primary active faults in California. In the 1990s' version they first included alternative models (epistemic uncertainties) using logic trees. The recent WGCEP 2003, 2007, 2013 reports are summarized in the following paragraphs.

The WGCEP (2003) study area is the SFBR. Monte Carlo simulations were used to obtain the SFBR logic tree branch weights. One of up to five different probability models was chosen for the earthquake probability of each fault. These models included: (1) a Poisson's or exponential distribution; (2) a Brownian Passage Time (BPT) model (Ellsworth et al. 1999); (3) a "BPT-step" model (Page and Carlson 2006); (4) a "time-predictable" model (Shimazaki and Nakata 1980); and (5) an "empirical" model (Reasenberg et al. 2003).

The WGCEP 2007 (2008) used uniform methodology for the earthquake probabilities for the entire state of California. They developed a moment-balanced method (Field et al. 2008) to make the models more consistent to observed long-term slip rate data. The WGCEP 2007 framework is comprised of four models: (1) a fault model; (2) a deformation model; (3) an earthquake rate model; and (4) a probability model.

Instead of using segmentation to establish fault models, the WGCEP 2013 subdivided each fault into equal length subsections, with lengths that are about half the seismogenic thickness, resulting in 2606 total subsections. The multifault ruptures were included via a generalized inversion approach (a system-level framework both for incorporating expert judgment and identifying a more complete range of models that are consistent with all available data). The time independent component result was presented in WGCEP
2013. The rates for all earthquakes were estimated from a broader range of data. WGCEP 2013 removed the apparent over-prediction of M 6.5 - 7 earthquake rates in WGCEP 2007. Although the WGCEP 2013 result fits the data better than WGCEP 2007 overall, there may be areas that warrant further site-specific investigation.

After the Great Hanshin-Awaji Earthquake Disaster in Japan on 17 January 1995, the Special Measure Law on Earthquake Disaster Prevention was enacted in July 1995. The Headquarters for Earthquake Research Promotion (HERP; HERP 2014) was established in accordance with this law. The purpose of HERP is to promote earthquake research to strengthen earthquake disaster prevention, especially the reduction of damages from earthquakes. The Earthquake Research Committee is a part of HERP, which evaluates seismic activity in a comprehensive manner and publishes evaluation results.

The latest earthquake occurrence probability results for major active faults in Japan were published in 2014. They evaluated the recurrence interval of active faults in two ways: (1) estimate the average in number of years according to the historical records of occurrence from the fault; (2) calculate the long-term slip rate $(\mathrm{V})$ and one event displacement (U) on the fault. The recurrence interval of this fault is $\mathrm{U} / \mathrm{V}$. Two different earthquake probability models were chosen. If the elapsed time was known the BPT model is chosen to estimate the earthquake occurrence probability. Otherwise, the Poisson's distribution model is chosen.

HERP also integrated the Probabilistic Seismic Hazard Maps (PSHM) and the result of subduction-Zone in Japan into a network information station called J-SHIS (http:// www.j-shis.bosai.go.jp/map/).

\section{CHARACTERIZATIONS OF ACTIVE FAULTS IN CENTRAL TAIWAN}

This article chose active faults in Central Taiwan as a case study for assessing earthquake probability. The Central Taiwan active faults in this article are shown in Fig. 1; including the Shihtan-Tuntzuchiao fault system, the Sanyi fault, the Tachia-Changhua fault system, the Chelungpu fault, and the Tamaopu-Shuangtung fault system. The Tiehchanshan fault is a back thrust of the Tachia fault and may not rupture independently, thus the Tiehchanshan fault was not taken into account for earthquake probability.

Figure 2 shows the geological cross-section in Central Taiwan. Most active faults from Central Taiwan are located in the western foothills belt. The western foothills Tertiary strata have been flexed into folds that trend east-northeast to north-northeast. With increased force pushing in the northwestward direction, the strata of the folds have been commonly broken through by west-verging thrust faults, resulting in imbricate fold-and-thrust belts.

This article collected the fault geometry parameters 
in Central Taiwan, which are summarized in the following items.

(1) Fault depth: in Central Taiwan the rupture depth of most faults ranges between $10-15 \mathrm{~km}$. However, the Chelungpu fault can reach $20 \mathrm{~km}$ based on observing 921 aftershocks distribution (Kao and Chen 2000).

(2) Dip angle: in addition to the Shihtan fault and the Tiehchanshan fault, the dip direction of most Taiwan's active faults is eastward. The dip angle of most thrust faults (some with strike-slip component) ranges between 30 - 60 degrees. The dip angle of pure strike-slip faults ranges between 70 - 90 degrees.

(3) Fault width: fault width was estimated using fault rupture depth $/ \sin \theta$, where $\theta$ is the fault dip.

(4) Fault area: fault area in Table 1 was estimated using fault length $\times$ fault width.

This article also gathered the last event time occurring in an active fault in Central Taiwan. This depends on

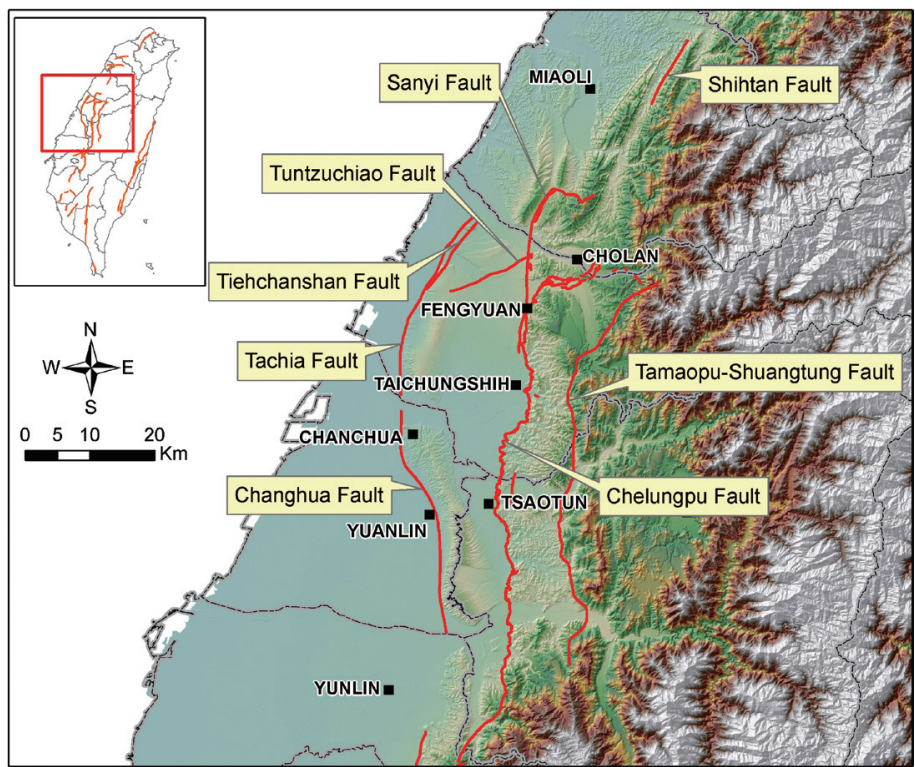

Fig. 1. Distribution map of the active faults in Central Taiwan. (Color online only)

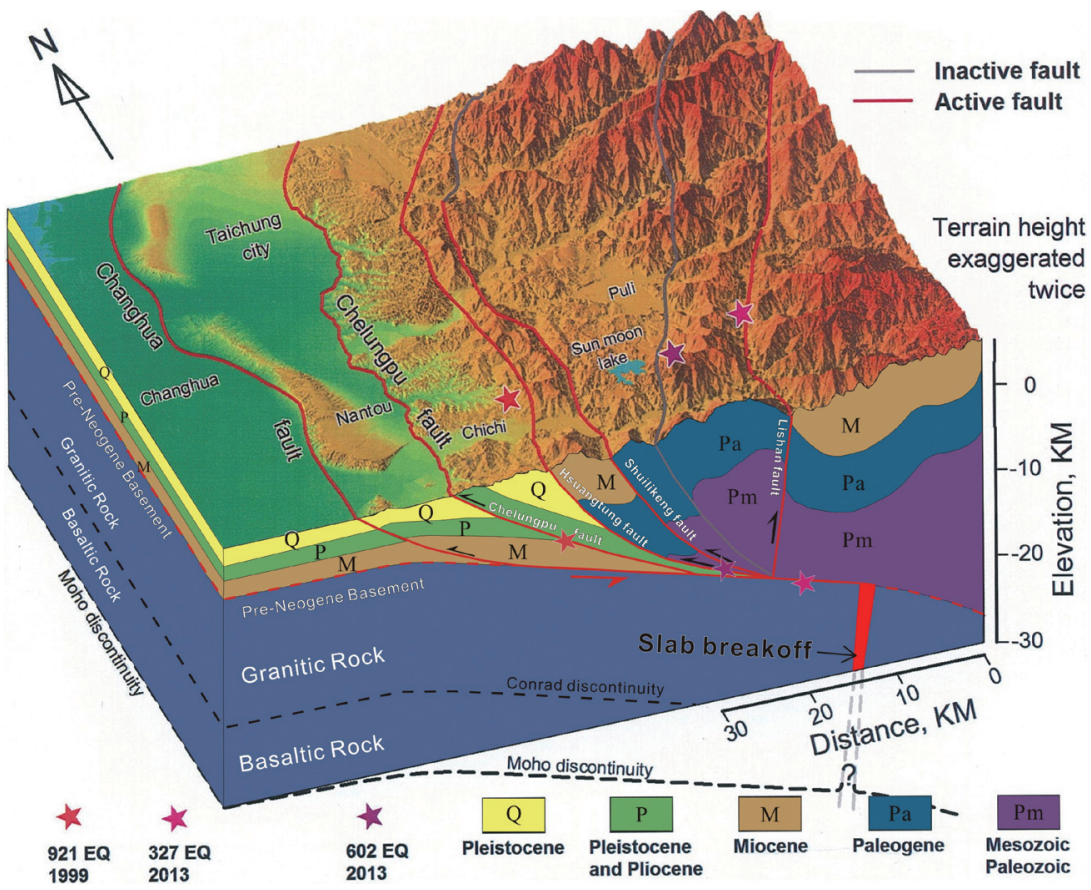

Fig. 2. Geologic cross-section in Central Taiwan (modified by Lee and Lin 2004). (Color online only) 


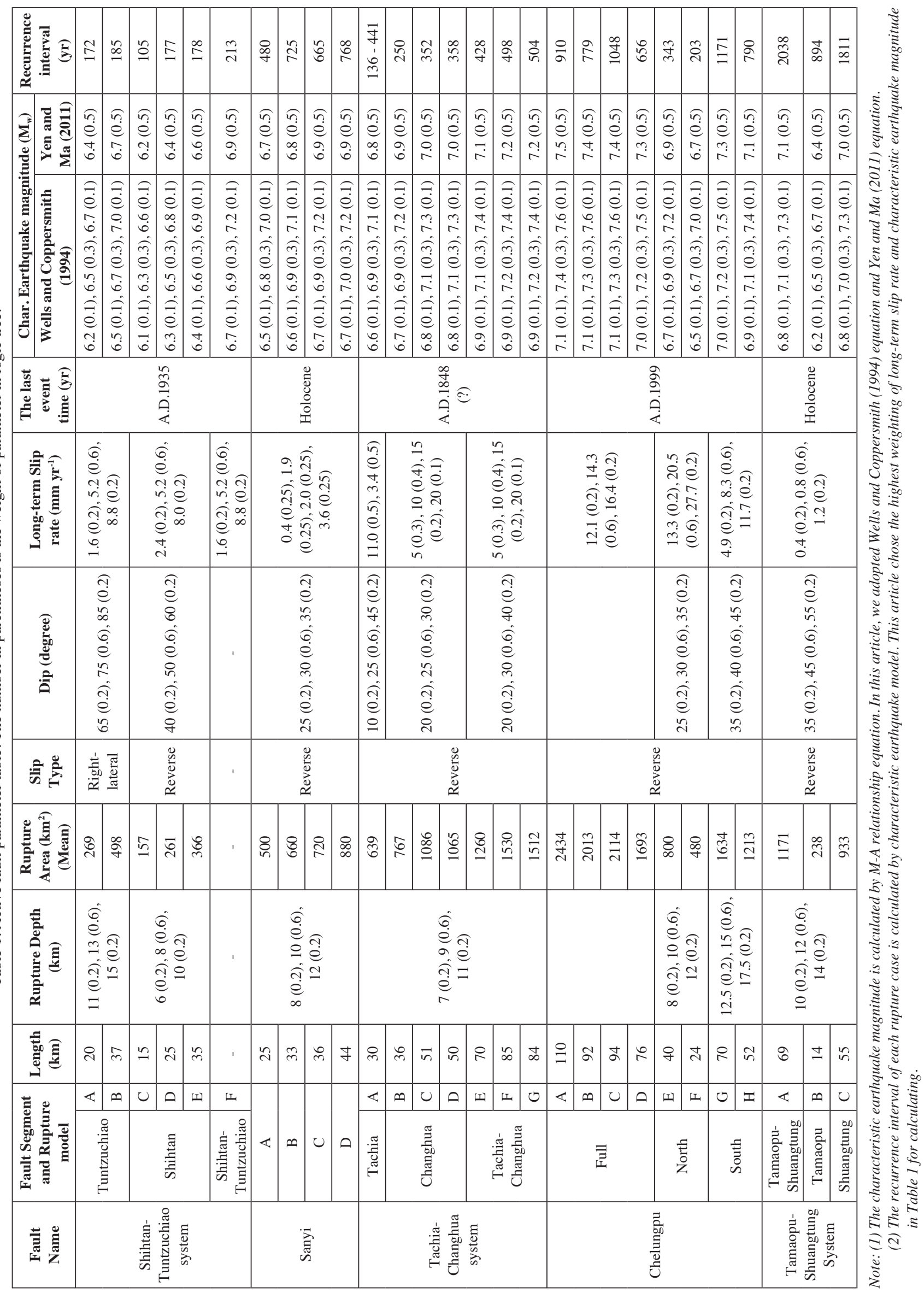


which probability model is used to assess the earthquake probability. The last event times at the Sanyi fault and the Tamaopu-Shuangtung fault are still unknown; the ShihtanTuntzuchiao fault system is 1935 A.D. $\left(\mathrm{M}_{\mathrm{w}}=7.1\right)$ (Sheu et al. 1982; Cheng 1995; Chen and Tsai 2008); the TachiaChanghua fault system is 1848 A.D. $\left(\mathrm{M}_{\mathrm{w}}=7.0\right)$; and the Chelungpu fault is 1999 A.D. $\left(M_{w}=7.6\right)$.

\section{METHODOLOGY}

\subsection{Procedures for Estimating Earthquake Probability at Active Faults}

This article classifies three Taiwan active fault scenarios from paleo-earthquake or elapsed time information from the last earthquake. The conceptual flow chart of these three scenarios is shown in Fig. 3 is the scenarios are described in the following paragraphs.

(1) If a fault had ruptured many times and the elapsed time from the last earthquake was available, the average recurrence interval and standard deviation were calculated using these paleo-earthquake intervals. Because of the earthquake cycle associated with the elastic rebound theory (Reid 1910), we chose the BPT model to assess the "time-dependent" earthquake probability. The BPT model properties satisfy the spirit of the hypothesis proposed by Reid (1910) and also provide more realistic asymptotic behavior for the failure rate than the alternative models. In one sense, the BPT model behaviour is similar to a delayed Poisson process, for which the conditional probability is zero for a finite time following an event and then steps up to an approximately constant conditional probability at all succeeding times.

(2) If we only understand the elapsed time from the last earthquake the recurrence interval is calculated using the characteristic earthquake model (Youngs and Coppersmith 1985). We used the $b$ value from the truncated exponential de-clustered catalogue model in shallow area sources, as partitioned by Cheng et al. (2015). We finally chose the BPT model to assess the earthquake probability of a fault.

(3) If the elapsed time was unknown, we still needed to evaluate the recurrence interval using U/V (U: one event displacement; V: long-term slip rate) or the characteristic earthquake model. We chose Poisson's model to assess the probability. Assuming a Poisson distribution implies that the events are statistically independent.

The schematic diagram of earthquake probability assessment on an active fault is shown in Fig. 4 and described in the following paragraphs.

Step 1. The first step is to collect the fault parameters, which include fault geometry (length, rupture depth, and dip), segmentation, and slip rate. We calculated the characteristic earthquake magnitude of each fault using its rupture area. Empirical source scaling equa- tions (e.g., Wells and Coppersmith 1994; Yen and Ma 2011) were used for this purpose.

Step 2 . With every possible case considered we needed to divide the fault segment to establish a rupture model. A fault rupture model is a weighted combination of the rupture cases for a fault. The long-term slip rate data can be applied in the characteristic earthquake model to obtain the recurrence interval. The gathered data were integrated as a fault parameter table (Table 1) for the following work.

Step 3. We calculated the earthquake recurrence interval using the characteristic earthquake model.

Step 4. Finally, we used the appropriate "probability model" to estimate the 30,50 , and 100 year conditional probability for $\mathrm{M} \geq 6.5$ and $\mathrm{M} \geq 7.0$ earthquakes.

\subsection{Logic Tree Concept in Considering the Model Uncertainties}

The earthquake probability model includes aleatory uncertainties and epistemic uncertainties. Aleatory uncertainty refers to the random variability that occurs in the natural world. Epistemic uncertainty refers to knowledge limitation about the natural world.

This article suggests the five logic tree branches include "fault segmentation and rupture model", "fault dip", "rupture depth", "long-term slip rate", and "characteristic earthquake magnitude $\left(\mathrm{M}_{\mathrm{w}}\right)$ ". The fault parameters are available using correspondence investigative techniques, which are shown in Table 2. Different investigative techniques may have different numbers for the same parameter, so we adopted expert opinions and a logic tree to account for the uncertainty in each step of the probability assessments. Expert consultation meetings were held to determine the fault parameter weights in the logic tree.

Figure 5 is an example of the Sanyi fault logic tree, which shows the logic tree branches, parameter numbers and their weights (in parentheses). The alternative parameters and their weights for active faults in Central Taiwan are also shown in Table 1.

\subsection{Fault Segmentation}

One fault usually ruptures in one of its segments, but not the entire length. Each segment has its own length and slip rate; thus, the earthquake magnitude and recurrence interval are not the same in different segments.

Faults could be subdivided into segments based on a variety of static geometric or geologic criteria. Lee (1993) listed eight criteria for fault segmentation, which are defined by

(1) Bend of fault trace,

(2) En echelon steps in fault trace,

(3) Geomorphic changes, 
(4) Intersections with other faults, folds, or cross structures,

(5) Enormous changes in bedrock or hydrologic environment,

(6) Changes in slip rates,

(7) Changes in elapsed times, and

(8) Faulting gaps.

In Japan the segmentation criteria for active faults include (1) the fault trace geometry (I. gap of more than $2 \mathrm{~km}$; II. bend of more than 20 degrees; III. step over; and IV. parallel faults separated by more than $2 \mathrm{~km}$ ) (Fig. 6); (2) the fault behavior (change in slip rate or slip direction); (3) paleo-seismicity (difference in faulting history); and (4) scaling law (one segment longer than 20000 times the slip per event should be divided into two) (Matsuda 1990).
In the United States, McCalpin (1996) also integrated the segment type subdivision. He thought that the historic rupture limits or prehistoric rupture limits defined by multiple, well dated paleo-earthquakes have more potential for use as an earthquake segment than the more static, indirect parameters.

The segmentation of active faults in Central Taiwan is generally defined in this study by CGS. We also referred to some published researches that divided the fault segment into alternative rupture cases in our rupture model, which are described in the following paragraphs.

In the Tachia-Changhua fault, the CGS said that the connection between the Changhua fault and the Tachia fault

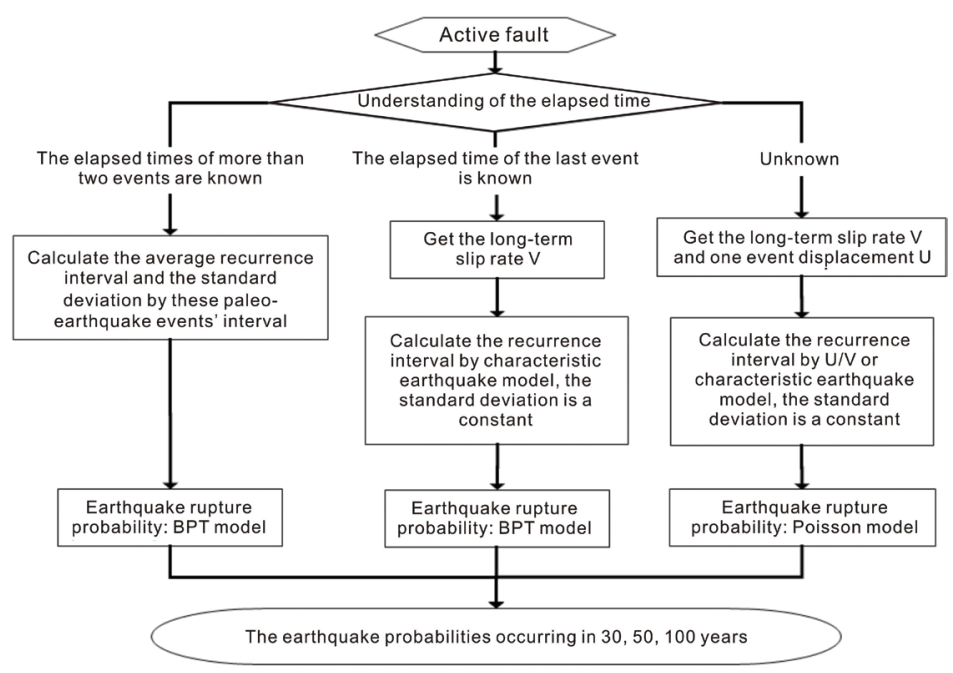

Fig. 3. Conceptual flow chart of earthquake probability assessment for active fault (modified from HERP 2001).
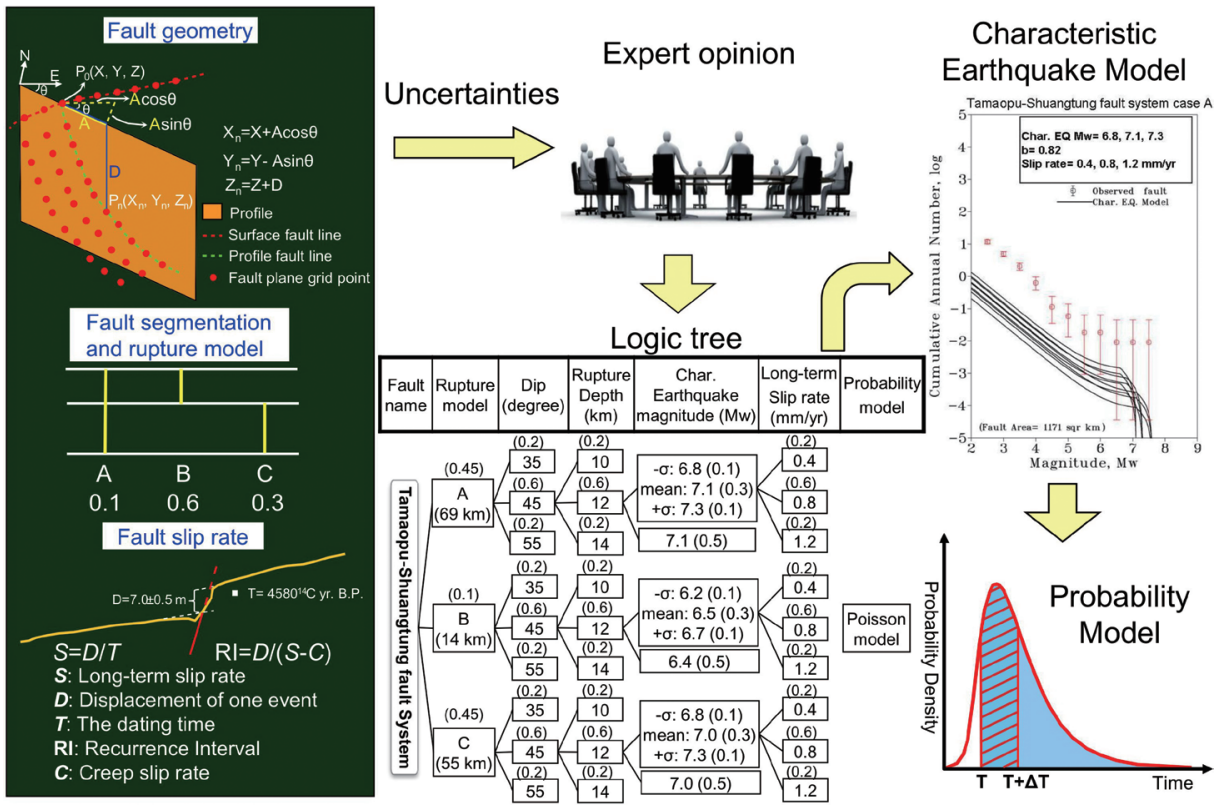

Fig. 4. Schematic diagram for estimating earthquake probability model for active faults. (Color online only) 
Table 2. The relationship between investigative techniques and fault parameters. The block dot means that the fault parameter is available in the corresponding column of the investigative technique.

\begin{tabular}{|c|c|c|c|c|c|}
\hline \multicolumn{2}{|c|}{$\begin{array}{ll}\text { Investigative Techniques } & \text { Fault Parameters } \\
\end{array}$} & \multirow{2}{*}{$\begin{array}{c}\text { Segmentation (Length) } \\
\bullet \bullet\end{array}$} & \multirow{2}{*}{$\begin{array}{c}\text { Fault Dip } \\
\bullet\end{array}$} & \multirow{2}{*}{$\begin{array}{c}\text { Rupture Depth } \\
\bullet\end{array}$} & \multirow{2}{*}{\begin{tabular}{|c|} 
Long-term Slip Rate \\
$\bullet$
\end{tabular}} \\
\hline \multirow{4}{*}{ Structural Geology } & Geologic cross-section & & & & \\
\hline & Tectonic sequence stratigraphy & $\bullet$ & & & \\
\hline & Balanced cross section & & $\bullet$ & $\bullet$ & $\bullet$ \\
\hline & Drilling boreholes & $\bullet$ & $\bullet$ & & \\
\hline \multirow{3}{*}{$\begin{array}{c}\text { Surface Geological } \\
\text { Survey }\end{array}$} & Earthquake surface rupture & $\bullet$ & & & \\
\hline & Exploratory trenching & & $\bullet$ & & $\bullet$ \\
\hline & Terrace dating & & & & - \\
\hline \multirow{2}{*}{ Exploration Geophysics } & Seismic profile & & $\bullet$ & $\bullet$ & \\
\hline & Resistivity Image Profile & $\bullet$ & & & \\
\hline \multirow{3}{*}{$\begin{array}{l}\text { Interpretation of Remote } \\
\text { Sensing Image }\end{array}$} & D-InSAR or PS-InSAR & $\bullet$ & & & \\
\hline & Satellite image interpretation & $\bullet$ & & & \\
\hline & Aerial photo interpretation & $\bullet$ & & & \\
\hline \multirow{4}{*}{ Seismology } & Aftershock distribution & $\bullet$ & & $\bullet$ & \\
\hline & Seismicity cross sections & & $\bullet$ & $\bullet$ & \\
\hline & Focal mechanism solution & & $\bullet$ & & \\
\hline & Seismic tomography & & & $\bullet$ & \\
\hline \multirow{2}{*}{ Geodetic survey } & GPS coseismic slip & $\bullet$ & & & \\
\hline & GPS block model & & & & $\bullet$ \\
\hline
\end{tabular}

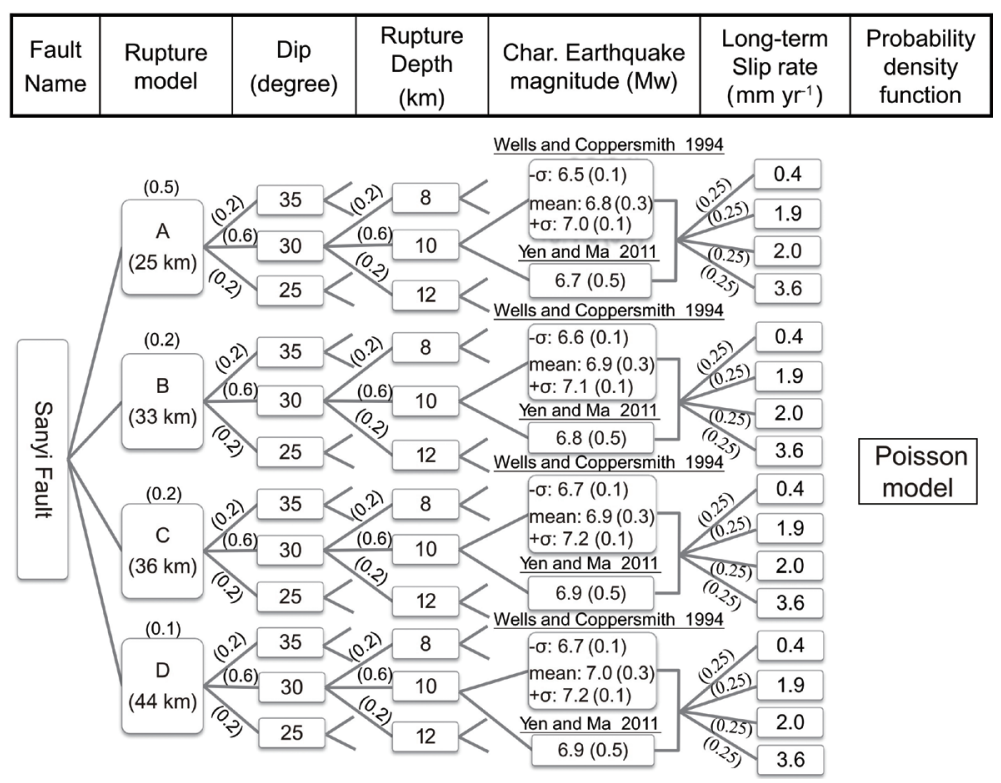

Fig. 5. Logic tree for the Sanyi fault. The parameters in logic tree are decided by experts' opinion in consulting meeting, and the number in parentheses are the weight of each parameter. 
Segmentation by surface geometry

1. Gap of more than $2 \mathrm{~km}$

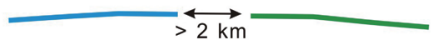

2. Bend of more than 20 degrees

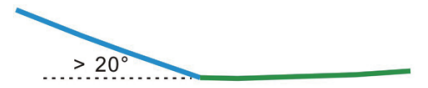

3. Stepover

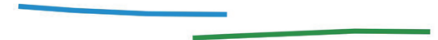

4. Parallel faults separated in more than $2 \mathrm{~km}$

$$
\uparrow>2 \mathrm{~km}
$$

Fig. 6. Specific segmentation criteria for active faults in Japan (Matsuda 1990). (Color online only)

is not clear because the morphology between these two faults is covered by alluvium (Lin et al. 2008). However, some researches considered the connection between these two faults (Lee and Lin 2004; Shyu et al. 2005; Cheng et al. 2007). Therefore, this study still considered the Changhua fault and the Tachia fault may connect to rupture together. The southern part of the Changhua fault may connect to the Tungshuhu fault (Lee and Lin 2004) or to the Chushan segment (Ota et al. 2002; Shyu et al. 2005), both of which were considered in our rupture cases.

In the Chelungpu fault the Chelungpu fault segmentation defined by Lee and Chan (2007) is based on the differences in scarp morphology, dip-angles and the Chi-Chi surface ruptures between the north (Fengyuan) and the south (Tsaotun) segments.

The Tamaopu-Shuangtung fault is probably cut by an east-trending strike-slip fault in the Tachiachi drainage area (Ho 1959). The north segment is called the Tamaopu fault; the south segment is called the Shuangtung fault.

The basic criteria of rupture cases and weights are shown in Figs. 7 and 8, which were determined using expert opinions in the expert consultation meeting. Figure 7 means that a fault may rupture in each segment $(\mathrm{A}, \mathrm{B}$, or $\mathrm{C})$ or in the whole segment. Figure 8 means that a fault may extend its rupture length to A' or A", but the extension part (A' and A") could not rupture independently.

However, there are still some exceptions. For example, in the Chelungpu fault rupture cases, the north segment had not ruptured independently according to the paleo-earthquake results using trenching data (Chen et al. 2007), so this article gave the north segment a lower weight than the south segment as well as the entire fault. In the TamaopuShuangtung fault rupture cases, because the length of the Tamaopu fault segment is too short to induce a large earthquake, this article gave 0.1 as the weight for the Tamaopu fault segment.

\subsection{Probability Assessment of an Active Fault}

\subsubsection{Recurrence Interval Estimation}

There are two models that can estimate the relationship between earthquake magnitude and recurrence rate. One is the truncated exponential model; the other is the characteristic earthquake model (Youngs and Coppersmith 1985).

The general form of the Gutenberg-Richter (Gutenberg and Richter 1954) exponential frequency magnitude relationship is

$\log \mathrm{N}(\mathrm{m})=\mathrm{a}-\mathrm{bm}$

Where $N(m)$ is the cumulative number of earthquakes of magnitude greater than $\mathrm{m}$, where $\mathrm{a}$ and $\mathrm{b}$ are constants.

Although the earthquake magnitude distribution on a seismic source is usually assumed to follow an exponential distribution, there is increasing evidence that a characteristic earthquake model may be more appropriate for individual faults (Schwartz and Coppersmith 1984; Davison and Scholz 1985; Youngs and Coppersmith 1985; Wesnousky 1994; Uchida et al. 2012). The characteristic earthquake model was also used for each rupture source in the Diablo Canyon Power Planet SSC (Seismic Source Characterization) model (Lettis et al. 2015) to estimate the relationship between earthquake magnitude and recurrence rate.

The characteristic earthquake model of Youngs and Coppersmith (1985) assumed that the characteristic earthquake magnitude ranges from $m_{u}-1 / 2$ to $m_{u}$. The characteristic portion of the magnitude frequency density function is a uniform distribution.

The cumulative rate is in the following set of equations:

$$
\begin{aligned}
\dot{\mathrm{N}}(\mathrm{m})= & \dot{\mathrm{N}}^{\mathrm{e}} \frac{\exp \left[-\beta\left(\mathrm{m}-\mathrm{m}_{0}\right)\right]-\exp \left[-\beta\left(\mathrm{m}_{\mathrm{u}}-1 / 2-\mathrm{m}_{0}\right)\right]}{1.0-\exp \left[-\beta\left(\mathrm{m}_{\mathrm{u}}-1 / 2-\mathrm{m}_{0}\right)\right]} \\
& +\dot{\mathrm{N}}^{\mathrm{c}} \text { for } \mathrm{m}_{0} \leq \mathrm{m}<\mathrm{m}_{\mathrm{u}}-\frac{1}{2} \\
\dot{\mathrm{N}}(\mathrm{m})= & \dot{\mathrm{N}}^{\mathrm{c}} \frac{\mathrm{m}_{\mathrm{u}}-\mathrm{m}}{1 / 2} \text { for } \mathrm{m}_{\mathrm{u}}-\frac{1}{2} \leq \mathrm{m}<\mathrm{m}_{\mathrm{u}}
\end{aligned}
$$

Where $\dot{\mathrm{N}}^{\mathrm{e}}$ and $\dot{\mathrm{N}}^{\mathrm{c}}$ are the cumulative rate of exponential and characteristic earthquakes respectively, $\mathrm{m}_{0}$ is the lower bound magnitude, $\mathrm{m}_{\mathrm{u}}$ is the upper bound magnitude; and $\mathrm{m}$ is the calculated magnitude, $\beta=\mathrm{b} \cdot \ln 10$.

$$
\begin{aligned}
& \text { The total cumulative annual rate where } \\
& \mathrm{m}_{\mathrm{u}}-\frac{1}{2} \leq \mathrm{m}<\mathrm{m}_{\mathrm{u}} \text { is: } \\
& \dot{\mathrm{N}}^{\mathrm{c}}=\mathrm{N}\left(\mathrm{m}_{\mathrm{u}}-\frac{1}{2}\right)
\end{aligned}
$$

The total cumulative annual rate where $\mathrm{m} \geq \mathrm{m}_{0}$ is: 
$\dot{\mathrm{N}}\left(\mathrm{m}_{0}\right)=\dot{\mathrm{N}}^{\mathrm{e}}+\dot{\mathrm{N}}^{\mathrm{c}}$

The $\dot{\mathrm{N}}^{\mathrm{e}}$ and $\dot{\mathrm{N}}^{\mathrm{c}}$ can be represented to fault area and fault slip rate:

$$
\begin{aligned}
\dot{\mathrm{N}}^{\mathrm{c}}= & \frac{1}{2} \dot{\mathrm{N}}^{\mathrm{e}} \frac{\mathrm{b} \ln 10 \cdot \exp \left[-\beta\left(\mathrm{m}_{\mathrm{u}}-3 / 2-\mathrm{m}_{0}\right)\right]}{\left\{1-\exp \left[-\beta\left(\mathrm{m}_{\mathrm{u}}-1 / 2-\mathrm{m}_{0}\right)\right]\right\}} \\
\dot{\mathrm{N}}^{\mathrm{e}}= & \frac{\mu \mathrm{A}_{\mathrm{f}} \mathrm{S} \cdot\left\{1-\exp \left[-\beta\left(\mathrm{m}_{\mathrm{u}}-\mathrm{m}_{0}-1 / 2\right)\right]\right\}}{\exp \left[-\beta\left(\mathrm{m}_{\mathrm{u}}-\mathrm{m}_{0}-1 / 2\right)\right] \cdot \mathrm{M}_{0}\left(\mathrm{~m}_{\mathrm{u}}\right) \cdot} \\
& {\left[\frac{\mathrm{b} \cdot 10^{-\mathrm{c} / 2}}{(\mathrm{c}-\mathrm{b})}+\frac{\mathrm{b} \cdot \exp (\beta)\left(1-10^{-\mathrm{c} / 2}\right)}{\mathrm{c}}\right] }
\end{aligned}
$$

Where $A_{f}$ is the fault area; $S$ is fault slip rate; $\mu$ is the rigidity shear modulus (here assumed $3 \times 10^{11}$ dyne $\left.\mathrm{cm}^{-2}\right) ; \mathrm{M}_{0}\left(\mathrm{~m}_{\mathrm{u}}\right)$ is the earthquake moment of $\mathrm{m}_{\mathrm{u}}$; and $\mathrm{c}$ and $\mathrm{d}$ are constants of the following equation:

$\log \left(\mathrm{M}_{0}\right)=\mathrm{cm}+\mathrm{d}$

Where $\mathrm{M}_{0}$ is the seismic moment; $\mathrm{m}$ is moment magnitude; $\mathrm{c}=1.5 ; \mathrm{d}=16.1$ (Hanks and Kanamori 1979).

Figure 9 is an example of the characteristic earthquake model for the Sanyi fault, which shows the relationship between magnitude and cumulative annual rate. This article uses four rupture cases for the Sanyi fault to calculate the relationship between magnitude and cumulative annual rate using the characteristic earthquake model. The observa- tion (red dots) data in Fig. 9 are chosen from shallow areal source, which was partitioned by Cheng et al. (2015). Because it is difficult to distinguish which seismicity was occurred by the active fault and the chosen numbers of seismicity from only an active fault are too small to calculate the annual rate, this study chose a shallow areal source to calculate and plot the cumulative annual rate. However, the seismicity rate of shallow area source which includes background seismicity and seismogenic structures. Therefore, its cumulative annual rate must be higher than the characteristic earthquake model of a single fault.

The calculated recurrence interval of each fault is shown in Table 1.

\subsubsection{Probability model}

The diagram for calculating conditional probability is shown in Fig. 10. The red line is the probability density function $f(t)$. The time interval of interest (exposure time) is from $\mathrm{T}$ (the present time) to $\mathrm{T}+\Delta \mathrm{T}$ (hachured area). The survivor function at time $\mathrm{T}$ is equal to the blue area. The conditional probability is the ratio of these two areas, which can be shown in the following set of equations:

$$
\begin{aligned}
& \mathrm{P}(\mathrm{T} \leq \mathrm{t} \leq \mathrm{T}+\Delta \mathrm{T} \mid \mathrm{t}>\mathrm{T})=\frac{\mathrm{F}(\mathrm{T})-\mathrm{F}(\mathrm{T}+\Delta \mathrm{T})}{\mathrm{F}(\mathrm{T})} \\
& \mathrm{F}(\mathrm{T})=\int_{\mathrm{T}}^{\infty} \mathrm{f}(\mathrm{t}) \mathrm{dt}
\end{aligned}
$$

The Poisson and BPT models were chosen in this study for

Two segment cases and weighting:

Three segment cases and weighting:
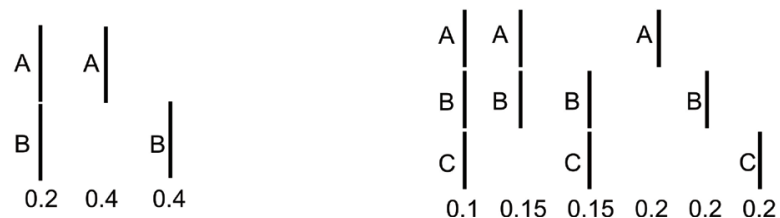

Fig. 7. Rupture case criteria and weights for fault segmentation in this study.
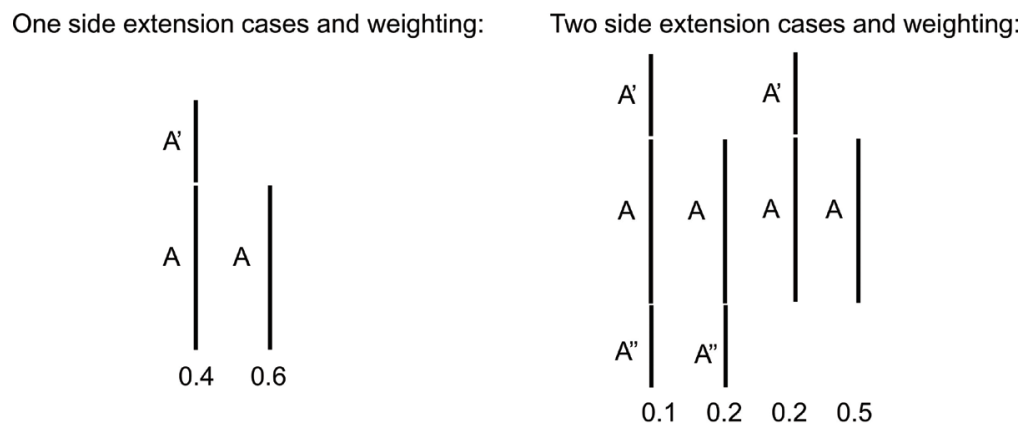

Fig. 8. Rupture case criteria and weights for fault extension in this study. 

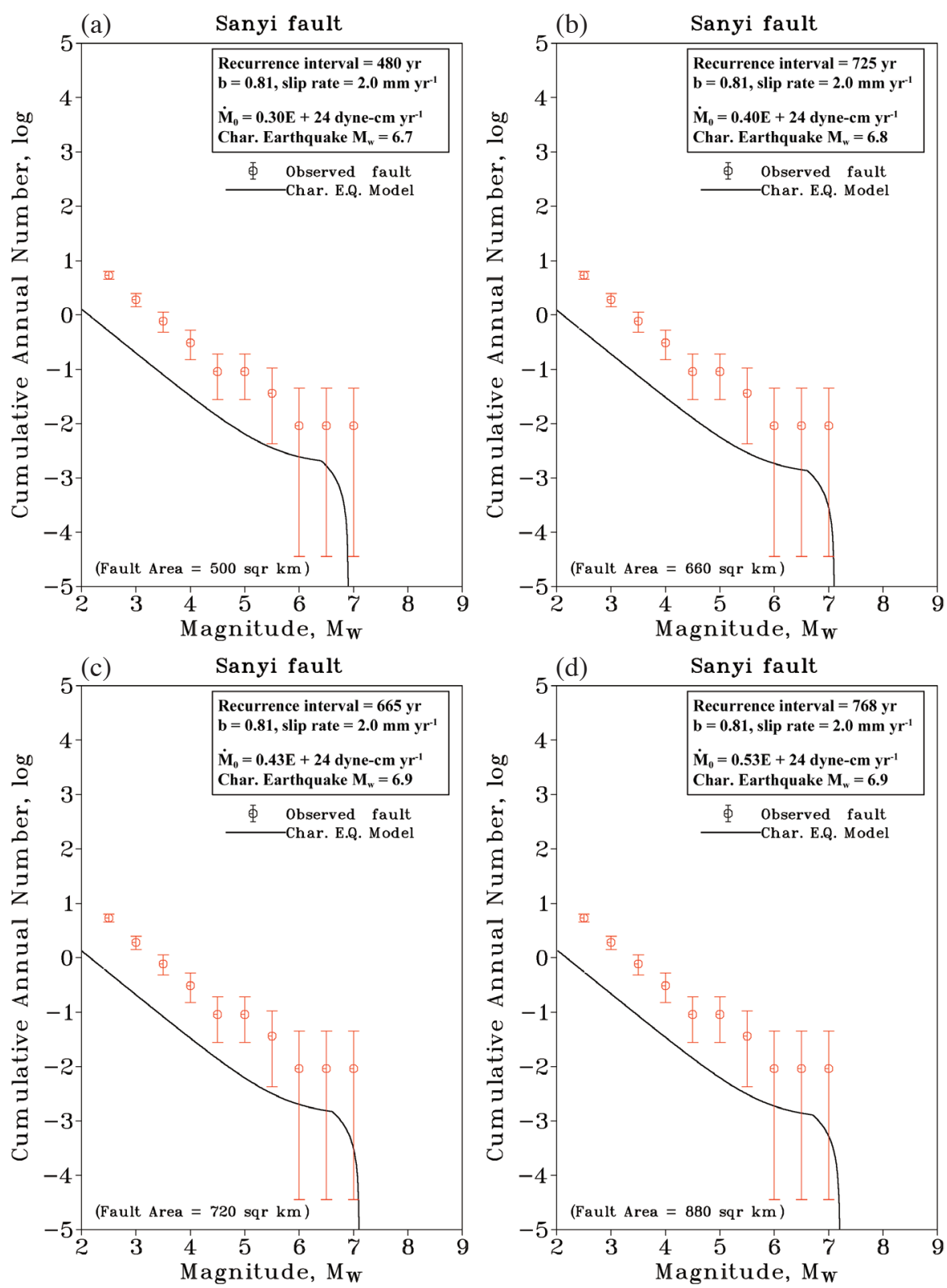

Fig. 9. The relationship between magnitude and cumulative annual number from four rupture cases of the Sanyi fault. The red points represent the seismicity data, and the length of the bars through the data points represent one standard deviation error bars. (Color online only)

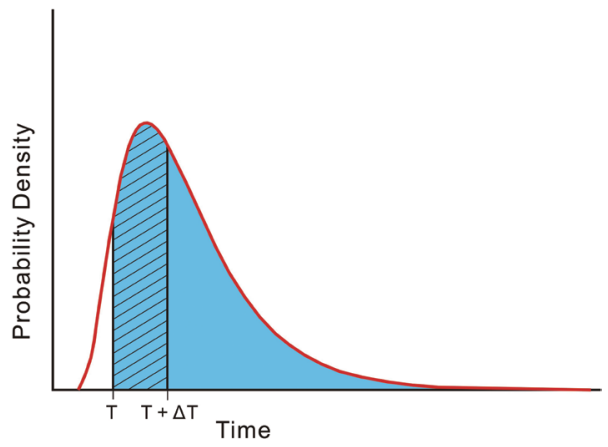

Fig. 10. Calculation of conditional probability from a probability density function. The time interval of interest (exposure time) is from $\mathrm{T}$ (the present time) to $\mathrm{T}+\Delta \mathrm{T}$ (hatchured area). The survivor function at time $\mathrm{T}$ is equal to the shaded area. The conditional probability is the ratio of these two areas. (Color online only) 
different conditions (see Fig. 3). These two models are described as follows.

\section{(1) Poisson model:}

The Poisson model describes the distribution of times between successive events for a homogeneous Poisson process (random occurrence) and is specified by the function:

$$
f_{\text {exp }}(t)=\lambda e^{-\lambda t}
$$

where $\lambda$ is the mean rate of events per unit time. In our calculations, $\lambda$ is the mean rupture rate of each rupture source, as determined by the long term model.

In the Poisson model conditional probabilities for a specified time interval depend only on the length of the interval, $\Delta t$, and the long-term rate of rupture for each source. The conditional probability for each source is given by

$$
1-\mathrm{e}^{-\lambda \Delta t}
$$

where $\Delta \mathrm{t}$ is 30,50 , or 100 years.

\section{(2) BPT model:}

In contrast to the Poisson model, a time-dependent renewal process model embodies the expectation that after one earthquake on a fault segment, another earthquake on that segment is unlikely until sufficient time has elapsed for stress to gradually re-accumulate (Lindh 1983; Sykes and Nishenko 1984; Nishenko and Buland 1987; Ellsworth 1995; Ogata 1999). Such models require a minimum of two parameters, and typically include knowledge of the time of the most recent rupture. One is the mean rate of events, $\mu$. The other, aperiodicity $(\alpha)$, is a measure of the irregularity of the length of the intervals between successive events. WGCEP (2003) chose sampling points for $\alpha$ (with relative weights) of $0.3(0.2), 0.5(0.5), 0.7(0.3)$. In Japan they chose $\alpha=$ 0.24 for BPT calculation. Analysis of 37 series of recurrent earthquakes in the world, Ellsworth et al. (1999) suggested a provisional generic value of $\alpha=0.5$, which can serve as a working estimate of the aperiodicity for recurrent earthquake sequences of all sizes and in all tectonic environments. We considered the variability of each fault adopting $0.3(0.2), 0.5$ $(0.5)$, and 0.7 (0.3) in this study as the BPT model's aperiodicity, which were included in our logic tree branches.

The BPT model (Kagan and Knopoff 1987; Ellsworth et al. 1999) is a renewal model that describes the rupture time statistical distribution. The probability density is defined by

$$
\mathrm{f}_{\mathrm{BPT}}(\mathrm{t})=\sqrt{\frac{\mu}{2 \pi \alpha^{2} \mathrm{t}^{3}}} \exp \left[-\frac{(\mathrm{t}-\mu)^{2}}{2 \alpha^{2} \mu \mathrm{t}}\right]
$$

Where $\mu$ is the mean rate of events, $\alpha$ is aperiodicity.
This study gathered fault data, which were integrated into a fault parameter table. The parameters and their weights for active faults in Central Taiwan are shown in Table 1. The segmentation and rupture cases for each fault are summarized in the following paragraphs.

(1) The Shihtan fault and the Tuntzuchiao fault may trigger each other, so the two faults can be considered as a Shihtan-Tuntzuchiao fault system. The rupture model can be divided into 3 types in the logic tree, which are the Shihtan fault rupture, the Tuntzuchiao fault rupture, and the Shihtan-Tuntzuchiao fault system rupture. The Shihtan fault rupture length can be divided into three cases $(15,25$, and $35 \mathrm{~km})$ based on the fault models of Lin et al. (2013). In addition, the Tuntzuchiao fault rupture length can be divided into two cases: the first has a surface rupture length of $20 \mathrm{~km}$; the second is $37 \mathrm{~km}$ long. Because the Shihtan fault is a triggered back thrust, this article gives low weights to the Shihtan fault cases. Thus, the summation weight for the three Shihtan fault cases is 0.2 . The possibility for the Shihtan-Tuntzuchiao fault system to rupture is even lower than that for the Shihtan fault because of the different faults types. This article gives the Shihtan-Tuntzuchiao fault system a weight of 0.1 . The Shihtan-Tuntzuchiao fault system rupture cases are shown in Fig. 11.

(2) The Sanyi fault can be divided into 4 rupture cases according to the northern and southern extensions. Case A is the central segment. Case B is the northern and central segment. Case $\mathrm{C}$ is the central and southern segment; and case D is the full segment (Fig. 12).

(3) The Tachia-Changhua fault rupture model can be divided into 3 types, which are the Tachia fault rupture (1 case), the Changhua fault rupture ( 3 cases), and the Tachia-Changhua fault rupture ( 3 cases). The weight of the Tachia fault rupture is 0.4 ; the Changhua fault rupture is 0.4 ; and the Tachia-Changhua fault rupture is 0.2 . In the Changhua fault rupture and Tachia-Changhua fault rupture cases, both of them can be subdivided into three cases according to the difference in the southern extension. The seven rupture cases are shown in Fig. 13.

(4) The Chelungpu fault rupture model can be divided into 3 types, which are the north segment rupture (2 cases), south segment rupture ( 2 cases), and the whole rupture (4 cases). Both the north segment rupture and the south segment can be subdivided into two cases based on their own extensions. The eight rupture cases are shown in Fig. 14.

(5) The Tamaopu-Shuangtung fault can be divided into 3 rupture cases. Case A is the whole segment; case B is the Tamaopu fault segment; and case C is the Shuangtung fault segment. The three rupture cases are shown in Fig. 15.

Table 3 shows the active fault probabilities in Central Taiwan. We used the appropriate "probability model" to

\section{ANALYSIS RESULT}




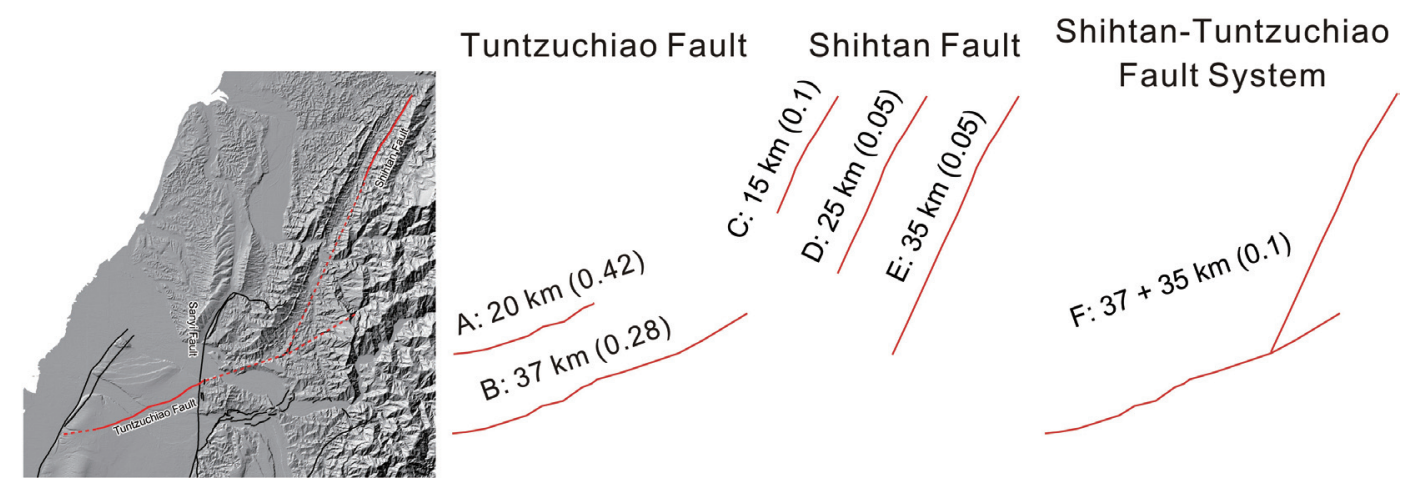

Fig. 11. Rupture cases and weights for the Shihtan-Tuntzuchiao fault system. (Color online only)

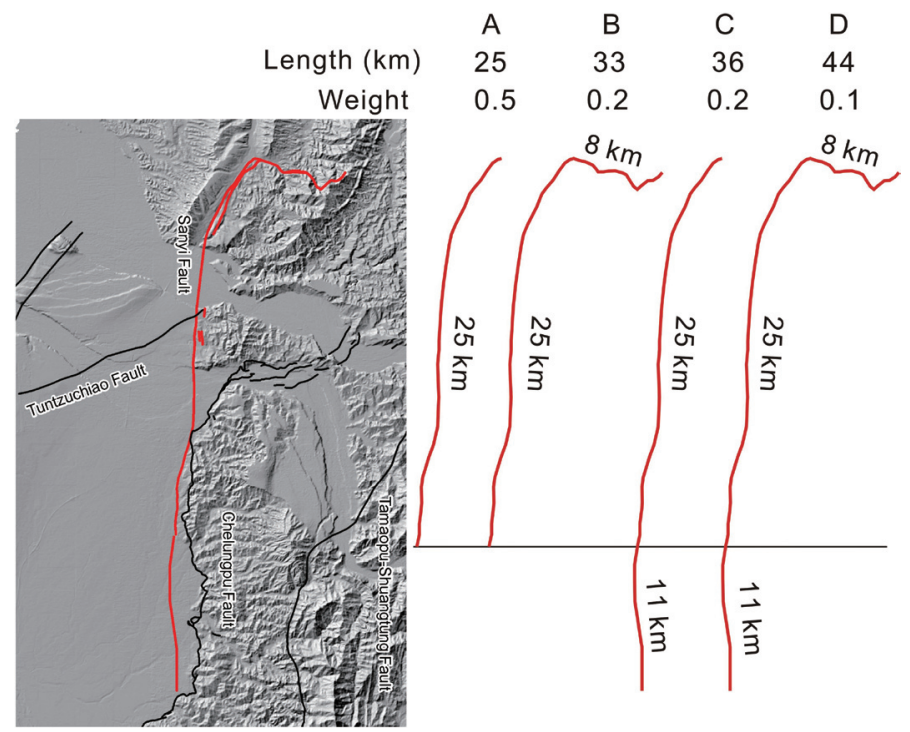

Fig. 12. Rupture cases for the Sanyi fault. (Color online only)

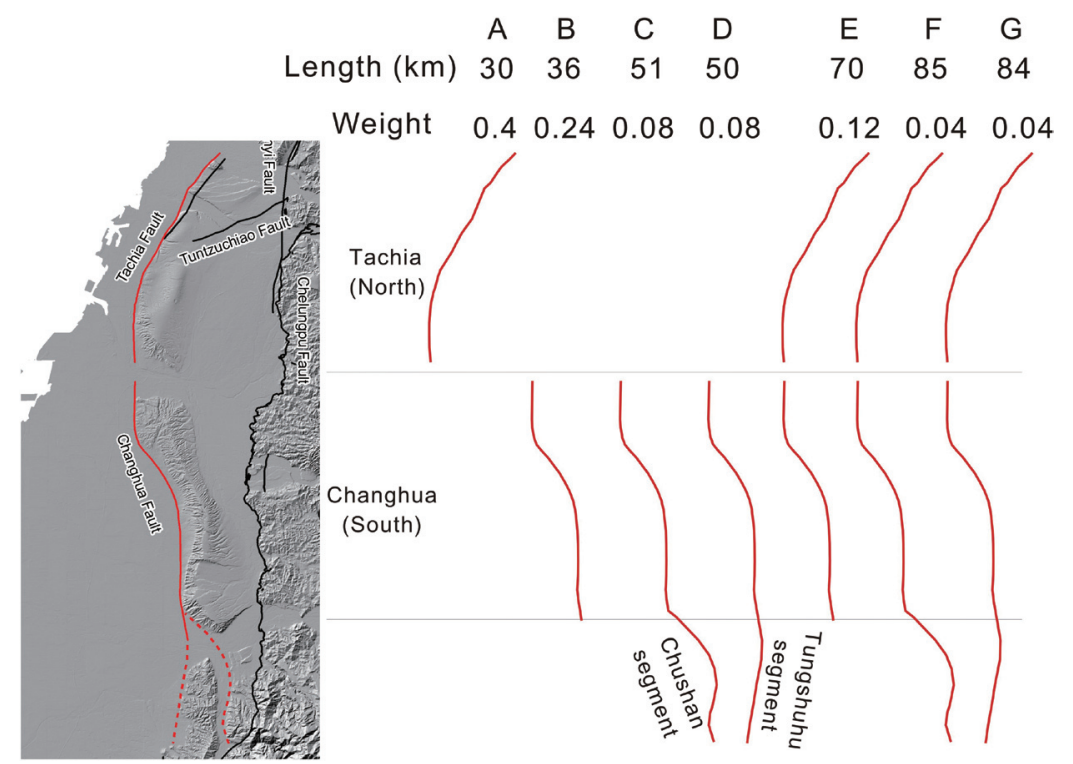

Fig. 13. Rupture cases for the Tachia-Changhua fault system. (Color online only) 


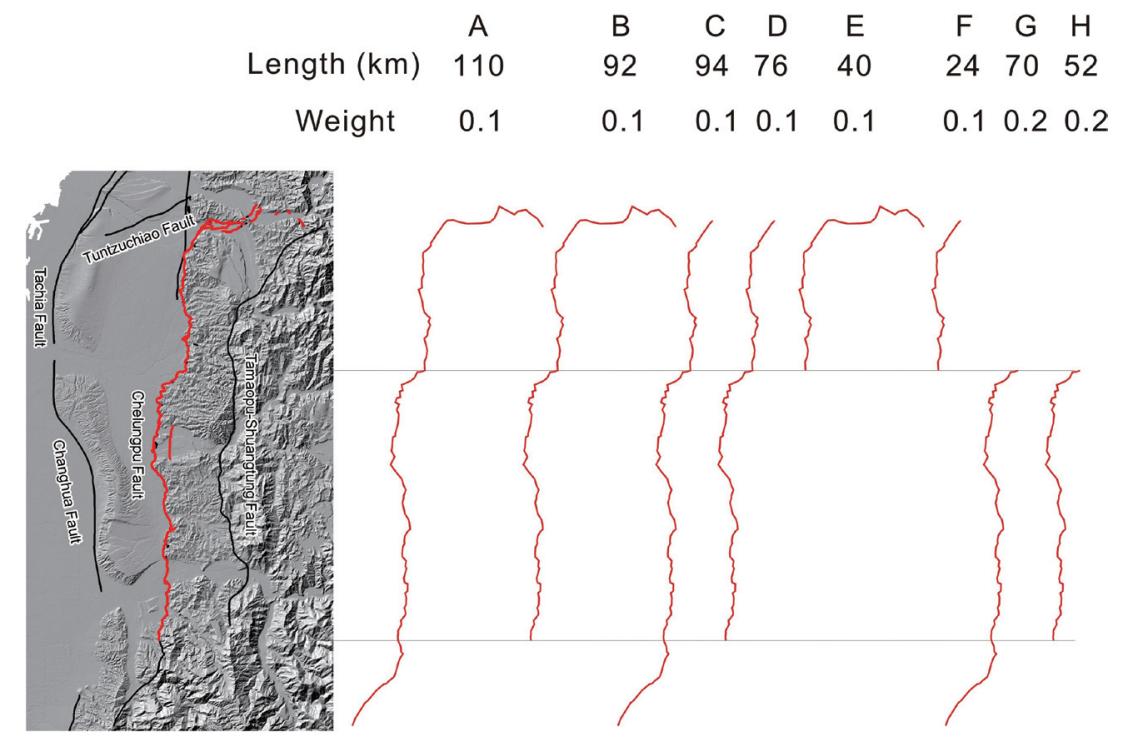

Fig. 14. Rupture cases for the Chelungpu fault. (Color online only)

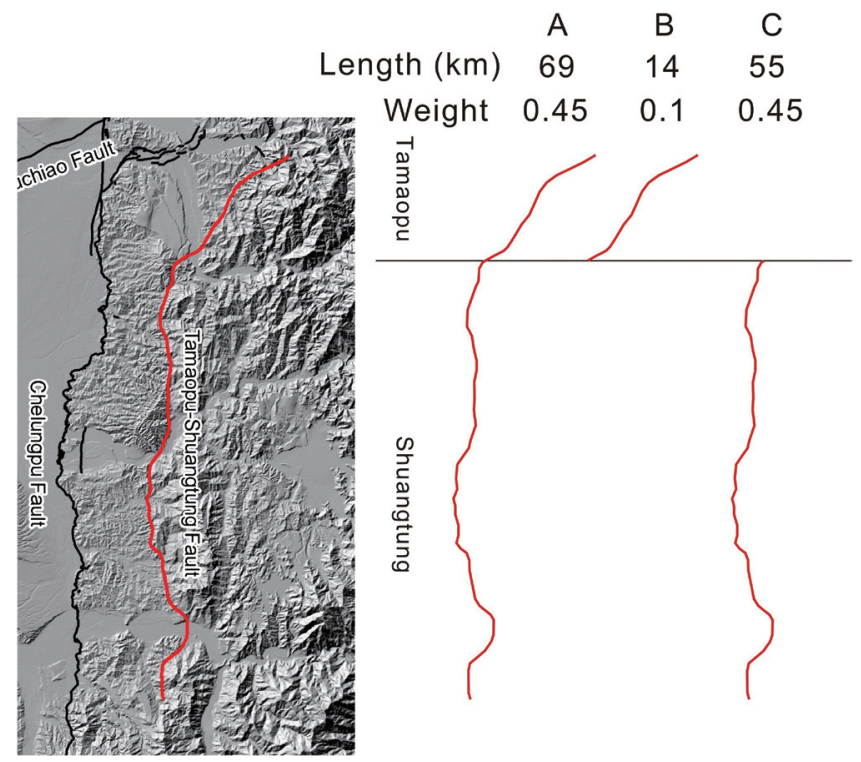

Fig. 15. Rupture cases for the Tamaopu-Shuangtung fault. (Color online only)

Table 3. Probabilities for active faults in Central Taiwan.

\begin{tabular}{|c|c|c|c|c|c|c|c|c|}
\hline \multirow{3}{*}{ Fault Name } & \multirow{3}{*}{$\begin{array}{c}\text { The last event time } \\
(\mathrm{yr})\end{array}$} & \multirow{3}{*}{ Probability model } & \multicolumn{6}{|c|}{ Conditional Probability } \\
\hline & & & \multicolumn{3}{|c|}{$M \geq 6.5$} & \multicolumn{3}{|c|}{$M \geq 7.0$} \\
\hline & & & 30 year & 50 year & 100 year & 30 year & 50 year & 100 year \\
\hline Shihtan-Tuntzuchiao system & A.D.1935 & BPT & $5.3 \%$ & $8.9 \%$ & $17.3 \%$ & $0.0 \%$ & $0.0 \%$ & $0.0 \%$ \\
\hline Sanyi & Holocene & POISSON & $4.4 \%$ & $7.2 \%$ & $13.6 \%$ & $0.2 \%$ & $0.4 \%$ & $0.7 \%$ \\
\hline Tachia-Changhua system & A.D. 1848 & BPT & $15.6 \%$ & $23.7 \%$ & $39.1 \%$ & $2.6 \%$ & $4.3 \%$ & $8.4 \%$ \\
\hline Chelungpu & A.D.1999 & BPT & $0.2 \%$ & $0.6 \%$ & $3.0 \%$ & $0.0 \%$ & $0.0 \%$ & $0.8 \%$ \\
\hline Tamaopu-Shuangtung & Holocene & POISSON & $1.4 \%$ & $2.3 \%$ & $4.5 \%$ & $0.7 \%$ & $1.1 \%$ & $2.2 \%$ \\
\hline
\end{tabular}


estimate the 30-, 50-, and 100-year conditional probability for $M \geq 6.5$ and $M \geq 7.0$ earthquakes. The probabilities for each fault are summarized in the following paragraphs.

(1) The Shihtan fault and Tuntzuchiao fault, which may trigger each other, can be considered as a Shihtan-Tuntzuchiao fault system. The BPT model was used for this fault system. The last event is set at year 1935. The results showed that the probabilities for a $\mathrm{M}_{\mathrm{w}} \geq 6.5$ earthquake occurring in 30,50 , and 100 years are 5.3, 8.9, and $17.3 \%$ respectively. The probabilities for a $\mathrm{M}_{\mathrm{w}} \geq 7.0$ earthquake occurring in 30,50 , and 100 years are 0.0 , 0.0 , and $0.0 \%$ respectively.

(2) The Poisson model was used for the Sanyi fault. The results showed that the probabilities for a $\mathrm{M}_{\mathrm{w}} \geq 6.5$ earthquake occurring in 30,50 , and 100 years are 4.4, 7.2, and $13.6 \%$ respectively. The probabilities for a $\mathrm{M}_{\mathrm{w}} \geq 7.0$ earthquake occurring in 30,50 , and 100 years are 0.2 , 0.4 , and $0.7 \%$ respectively.

(3) This article considers the fact that the Tachia fault may rupture together with the Changhua fault. The last event is set at year 1848. The BPT model was used for this fault system. The probabilities for $\mathrm{a}_{\mathrm{w}} \geq 6.5$ earthquake occurring in 30, 50, and 100 years are 15.6, 23.7, and $39.1 \%$ respectively. The probabilities for a $\mathrm{M}_{\mathrm{w}} \geq 7.0$ earthquake occurring in 30, 50, and 100 years are 2.6, 4.3 , and $8.4 \%$ respectively.

(4) The last event for the Chelunpu fault is set at year 1999. The BPT model was used for this fault. The results showed that the probabilities for a $\mathrm{M}_{\mathrm{w}} \geq 6.5$ earthquake occurring in 30,50 , and 100 years are $0.2,0.6$, and $3.0 \%$ respectively. The probabilities for $\mathrm{a}_{\mathrm{w}} \geq 7.0$ earthquake occurring in 30,50 , and 100 years are $0.0,0.0$, and $0.8 \%$ respectively.

(5) The Poisson model was used for the Tamaopu-Shuangtung fault. The results showed that the probabilities for a $M_{w} \geq 6.5$ earthquake occurring in 30,50 , and 100 years are $1.4,2.3$, and $4.5 \%$ respectively. The probabilities for $a M_{w} \geq 7.0$ earthquake occurring in 30,50 , and 100 years are $0.7,1.1$, and $2.2 \%$ respectively.

\section{DISCUSSION}

There are possibilities that should be considered when establishing fault rupture models for active faults, including (1) systemic rupture between two active faults, (2) the extendable length of one fault, and (3) the existence of blind fault.

There are many uncertainties when choosing a long term slip rate. For example, the geologic data that we used to calculate the long term slip rate is not available in some active faults. In addition, the long term slip rate observed from surface geologic data cannot represent the cumulative energy in deep fault plane. The slip distribution on the whole fault plane can be estimated by inversion of geodetic data, but the observed time of geodetic data is too short to represent the long term slip rate. The slip vector on fault plane is also a type of uncertainty. Thus, the uncertainty of long term slip rate is still larger than other parameters.

We adopted the following methods in this article to cope with the epistemic uncertainty of long term slip rate. If the geologic data (exploratory trenching, drilling, and geomorphic features) were sufficient to calculate the long term slip rate, we used results from geologic data as long term slip rate for the fault. Otherwise, we need to establish an inversion model using geodetic arrays. The rates of deformation across a specific fault can be calculated by the inversion model. Additionally, if a fault had aseismic slip (e.g., the Chihshang fault in Eastern Taiwan), we need to reduce the seismic moment according to the proportion of the released aseismic energy. After estimating the slip rate of each fault in Taiwan, we need to compare this with the regional plate motion to make sure that they are consistent. In terms of slip vector, we can use the rake on fault plane as a logic tree branch to cope with the uncertainty of slip vector. Finally, we adopted expert opinion and logic tree to solve the problem of uncertainties.

During the assessment process we found that the recurrence interval for some active faults is too short to match the historical record. Due to the short length and high slip rate of some active faults in Southern Taiwan, such as the Hsinhua fault, the Tsochen fault, and the Hsiaokangshan fault, the recurrence interval could be less than 100 years in the characteristic earthquake model. We assume that not all relationships between earthquake magnitude and recurrence rate are consistent with the characteristic earthquake model, perhaps consistent with the Gutenberg-Richter relationship. In the future, we need to choose correspondent model based on the realistic record or the active feature of each fault.

\section{CONCLUSION}

This study described a process for estimating earthquake probability assessment for active faults based on experiences from Japan and the United States. The procedure includes the construction of a logic tree, fault segmentation criteria, characteristic earthquake model and statistical models. We used the active faults in Central Taiwan as a case study to calculate the earthquake probability.

Our results showed that the highest earthquake probability where a $\mathrm{M}_{\mathrm{w}} \geq 6.5$ earthquake could occur in 30,50 , and 100 years in Central Taiwan is the Tachia-Changhua fault system. Conversely, the lowest earthquake probability is the Chelungpu fault.

The future goal of our research is to calculate the earthquake probability for the 33 active faults in Taiwan. The active fault parameters are important information that can be applied to seismic hazard analysis and seismic simulations.

If the parameters for an active fault are not clear when 
collecting data we will suggest the Central Geologic Survey conduct a more detailed investigation for this fault. We also might suggest that a fault with high earthquake probability should be monitored constantly to prevent and mitigate the forecast earthquake disaster.

Acknowledgements This work was supported by the Central Geological Survey, MOEA (CGS102-5226904000-0601, CGS103-5226904000-04-01). Special thanks to Dr. Jian-Cheng Lee for very stimulating and knowledgeable discussions and comments. We are deeply grateful to two reviewers for critical comments and wise suggestions on this paper.

\section{REFERENCES}

Angelier, J., 1986: Preface. Tectonophysics, 125, IX-X, doi: 10.1016/0040-1951(86)90003-X. [Link]

Bonilla, M. G., 1977: Summary of Quaternary faulting and elevation changes in Taiwan. Mem. Geol. Soc. China, 2, 43-55.

Chen, K. P. and Y. B. Tsai, 2008: A catalog of Taiwan earthquakes (1900-2006) with homogenized $M_{\mathrm{w}}$ magnitudes. Bull. Seismol. Soc. Am., 98, 483-489, doi: 10.1785/0120070136. [Link]

Chen, W. S., C. C. Yang, I. C. Yen, L. S. Lee, K. J. Lee, H. C. Yang, H. C. Chang, Y. Ota, C. W. Lin, W. H. Lin, T. S. Shih, and S. T. Lu, 2007: Late Holocene paleoseismicity of the southern part of the Chelungpu Fault in central Taiwan: evidence from the Chushan excavation site. Bull. Seismol. Soc. Am., 97, 1-13, doi: 10.1785/0120050161. [Link]

Cheng, C. T., 2002: Uncertainty analysis and deaggregation of seismic hazard in Taiwan. Ph.D. Thesis, National Central University, Taoyuan City, Taiwan, 227 pp. (in Chinese)

Cheng, C. T., S. J. Chiou, C. T. Lee, and Y. B. Tsai, 2007: Study on probabilistic seismic hazard maps of Taiwan after Chi-Chi earthquake. J. GeoEngineering, 2, 19-28.

Cheng, C. T., P. S. Hsieh, P. S. Lin, Y. T. Yen, and C. H. Chan, 2015: Probability seismic hazard mapping of Taiwan. Encyclopedia of Earthquake Engineering, Springer Berlin Heidelberg, 1-25, doi: 10.1007/978-3642-36197-5_100-1. [Link]

Cheng, S. N., 1995: The study of stress distribution in and around Taiwan. Ph.D. Thesis, National Central University, Taoyuan City, Taiwan, 215 pp. (in Chinese)

Davison, F. C. and C. H. Scholz, 1985: Frequency-moment distribution of earthquakes in the Aleutian Arc: A test of the characteristic earthquake model. Bull. Seismol. Soc. Am., 75, 1349-1361.

Ellsworth, W. L., 1995: Characteristic earthquakes and long-term earthquake forecasts: Implications of central California seismicity. In: Cheng, F. Y. and M. S. Sheu
(Eds.), Urban Disaster Mitigation: The Role of Engineering and Technology, Elsevier, 1-14, doi: 10.1016/ B978-008041920-6/50007-5. [Link]

Ellsworth, W. L., M. V. Matthews, R. M. Nadeau, S. P. Nishenko, P. A. Reasenberg, and R. W. Simpson, 1999: A physically-based earthquake recurrence model for estimation of long-term earthquake probabilities. Open-File Report 99-522, U.S. Geological Survey, Reston, VA, 22 pp. Available at https://pubs.er.usgs. gov/publication/ofr99522.

Field, E. H., R. J. Weldon II, T. Parsons, C. J. Wills, T. E. Dawson, R. S. Stein, and M. D. Petersen, 2008: Development of final A-fault rupture models for WGCEP/ NSHMP Earthquake Rate Model 2. Open-File Report 2007-1437, Version 1.0, U.S. Geological Survey, 59 pp. Available at https://pubs.er.usgs.gov/publication/ ofr20071437G.

Gutenberg, B. and C. F. Richter, 1954: Seismicity of the Earth and Associated Phenomena, Princeton University Press, Princeton, New Jersey, 310 pp.

Hanks, T. C. and H. Kanamori, 1979: A moment magnitude scale. J. Geophys. Res., 84, 2348-2350, doi: 10.1029/ JB084iB05p02348. [Link]

Headquarters for Earthquake Research Promotion (HERP), 2014: The National Seismic Hazard Maps for Japan 2014 version.

Ho, C. S., 1959: Thrust Structures in Taichung and Nantou, Central Taiwan. Bull. Geol. Surv. Taiwan, 11, 65-79.

Hsu, T. L. and H. C. Chang, 1979: Quaternary faulting in Taiwan. Mem. Geol. Soc. China, 3, 155-165.

Kagan, Y. Y. and L. Knopoff, 1987: Random stress and earthquake statistics: Time dependence. Geophys. J. Int., 88, 723-731, doi: 10.1111/j.1365-246X.1987. tb01653.x. [Link]

Kao, H. and W. P. Chen, 2000: The Chi-Chi earthquake sequence: Active, out-of-sequence thrust faulting in Taiwan. Science, 288, 2346-2349, doi: 10.1126/science.288.5475.2346. [Link]

Lee, C. T., 1993: New development of active fault engineering evaluation. Sino-Geotechnics, 44, 05-18. (in Chinese)

Lee, C. T., 1999: Neotectonics and active faults in Taiwan. Workshop on Disaster Prevention/Management and Green Technology, Foster City, California, 61-74.

Lee, C. T. and P. S. Lin, 2004: Active faults and seismic hazards in west central Taiwan. International Conference in Commemoration of 5th Anniversary of the 1999 Chi-Chi Earthquake, Taiwan. Vol. 27, 27-42.

Lee, J. C. and Y. C. Chan, 2007: Structure of the 1999 ChiChi earthquake rupture and interaction of thrust faults in the active fold belt of western Taiwan. J. Asian Earth Sci., 31, 226-239, doi: 10.1016/j.jseaes.2006.07.024. [Link]

Lettis, W., H. AbramsonWard, G. Biasi, J. Caskey, K. 
Hanson, and S. Thompson, 2015: Seismic Source Characterization for the Diablo Canyon Power Plant, San Luis Obispo County, California. Report on the results of a SSHAC level 3 study, $652 \mathrm{pp}$.

Lin, C. W., S. T. Lu, T. S. Shih, W. H. Lin, Y. C. Liu, and P. T. Chen, 2008: Active faults of central Taiwan: Explanatory text for the strip maps of active faults scale 1:25,000. Spec. Publ. Cent. Geol. Surv., 21, 1-148.

Lin, D. H., K. H. Chen, R. J. Rau, and J. C. Hu, 2013: The role of a hidden fault in stress triggering: Stress interactions within the $1935 \mathrm{Mw} 7.1 \mathrm{Hsinchu-Taichung} \mathrm{earth-}$ quake sequence in central Taiwan. Tectonophysics, 601, 37-52, doi: 10.1016/j.tecto.2013.04.022. [Link]

Lindh, A. G., 1983: Preliminary assessment of long-term probabilities for large earthquakes along selected fault segments of the San Andreas fault system in California. Open-File Report 83-63, U.S. Geological Survey, 15 pp. Available at https://pubs.er.usgs.gov/publication/ofr8363.

Matsuda, T., 1990: Seismic zoning map of Japanese islands, with maximum magnitudes derived from active fault data. Bull. Earthq. Res. Inst., 65, 289-319. (in Japanese)

McCalpin, J. P., 1996: Application of paleoseismic data to seismic hazard Assessment and neotectonic research. In: McCalpin, J. P. (Ed.), International Geophysics: Paleoseismology, Vol. 62, Elsevier, 439-493, doi: 10.1016/S0074-6142(96)80076-3. [Link]

Nishenko, S. P. and R. Buland, 1987: A generic recurrence interval distribution for earthquake forecasting. Bull. Seismol. Soc. Am., 77, 1382-1399.

Ogata, Y., 1999: Estimating the hazard of rupture using uncertain occurrence times of paleoearthquakes. J. Geophys. Res., 104, 17995-18014, doi: 10.1029/1999JB900115. [Link]

Ota, Y., J. B. H. Shyu, Y. G. Chen, and M. L. Hsieh, 2002: Deformation and age of fluvial terraces south of the Choushui River, Central Taiwan, and their tectonic implications. West. Pac. Earth Sci., 2, 251-260.

Page, M. T. and J. M. Carlson, 2006: Methodologies for earthquake hazard assessment: Model uncertainty and the WGCEP-2002 forecast. Bull. Seismol. Soc. Am., 96, 1624-1633, doi: 10.1785/0120050195. [Link]

Reasenberg, P. A., T. C. Hanks, and W. H. Bakun, 2003: An empirical model for earthquake probabilities in the San Francisco Bay Region, California, 2002-2031. Bull. Seismol. Soc. Am., 93, 1-13, doi: 10.1785/0120020014. [Link]

Reid, H. F., 1910: The mechanics of the earthquake, the California earthquake of April 18, 1906. Report of the State Earthquake Investigation Commission, publication no. 87, Carnegie Institution of Washington, Vol. II, $192 \mathrm{pp}$.

Schwartz, D. P. and K. J. Coppersmith, 1984: Fault behav- ior and characteristic earthquakes: Examples from the Wasatch and San Andreas Fault Zones. J. Geophys. Res., 89, 5681-5698, doi: 10.1029/JB089iB07p05681. [Link]

Seno, T., 1977: The instantaneous rotation vector of the Philippine sea plate relative to the Eurasian plate. Tectonophysics, 42, 209-226, doi: 10.1016/00401951(77)90168-8. [Link]

Sheu, H. C., M. Kosuga, and H. Sato, 1982: Mechanism and fault model of the Hsinchu-Taichung (Taiwan) earthquake of 1935. Zisin, 35, 567-574. (in Japanese)

Shimazaki, K. and T. Nakata, 1980: Time-predictable recurrence model for large earthquakes. Geophys. Res. Lett., 7, 279-282, doi: 10.1029/GL007i004p00279. [Link]

Shyu, J. B. H., K. Sieh, Y. G. Chen, and C. S. Liu, 2005: Neotectonic architecture of Taiwan and its implications for future large earthquakes. J. Geophys. Res., 110, B08402, doi: 10.1029/2004JB003251. [Link]

Sykes, L. R. and S. P. Nishenko, 1984: Probabilities of occurrence of large plate rupturing earthquakes for the San Andreas, San Jacinto, and Imperial faults, California, 1983-2003. J. Geophys. Res., 89, 5905-5927, doi: 10.1029/JB089iB07p05905. [Link]

Tsai, Y. B., C. Y. Wang, C. T. Lee, M. H. Hsu, and K. S. Liu, 1998: The research of active fault investigation near Junior high school and elementary school and earthquake prevention countermeasure in Taiwan. The Report of Education Department, Taiwan Provincial Government. (in Chinese)

Uchida, N., T. Matsuzawa, W. L. Ellsworth, K. Imanishi, K. Shimamura, and A. Hasegawa, 2012: Source parameters of microearthquakes on an interplate asperity off Kamaishi, NE Japan over two earthquake cycles. Geophys. J. Int., 189, 999-1014, doi: 10.1111/j.1365246X.2012.05377.x. [Link]

Wells, D. L. and K. J. Coppersmith, 1994: New empirical relationships among magnitude, rupture length, rupture width, rupture area, and surface displacement. Bull. Seismol. Soc. Am., 84, 974-1002.

Wesnousky, S. G., 1994: The Gutenberg-Richter or characteristic earthquake distribution, which is it? Bull. Seismol. Soc. Am., 84, 1940-1959.

Working Group on California Earthquake Probabilities (WGCEP), 2003: Earthquake probabilities in the San Francisco Bay region: 2002-2031. Open-File Report 03-214, U.S. Geological Survey, 234 pp. Available at http://pubs.usgs.gov/of/2003/of03-214/.

Working Group on California Earthquake Probabilities 2007 (WGCEP 2007), 2008: The uniform California earthquake rupture forecast, version 2 (UCERF 2). USGS Open File Report 2007-1437, CGS Special Report 203, SCEC Contribution \#1138, Version 1.1, U.S. Geological Survey, 96 pp. Available at http://pubs.usgs.gov/ of/2007/1437/. 
Yen, Y. T. and K. F. Ma, 2011: Source-scaling relationship for M 4.6-8.9 earthquakes, specifically for earthquakes in the collision zone of Taiwan. Bull. Seismol. Soc. Am., 101, 464-481, doi: 10.1785/0120100046. [Link]

Youngs, R. R. and K. J. Coppersmith, 1985: Implications of fault slip rates and earthquake recurrence models to probabilistic seismic hazard estimates. Bull. Seismol. Soc. Am., 75, 939-964.

Yu, S. B., H. Y. Chen, and L. C. Kuo, 1997: Velocity field of GPS stations in the Taiwan area. Tectonophysics, 274, 41-59, doi: 10.1016/S0040-1951(96)00297-1. [Link] 